\begin{tabular}{|c|l|}
\hline Title & $\begin{array}{l}\text { So, what do we know and what do we need to know more about the population ecology of the vole Clethrionomys } \\
\text { rufocanus? }\end{array}$ \\
\hline Author(s) & Stenseth, Nils Chr.; Saitoh, Takashi \\
\hline Citation & $\begin{array}{l}\text { Researches on population ecology, 40(1), 153-158 } \\
\text { https://doi.org/10.1007/pf02765235 }\end{array}$ \\
\hline Issue Date & 1998 \\
\hline Doc URL & http://hdl.handle.net/2115/16992 \\
\hline Type & article \\
\hline File Information & RPE40-1-153.pdf \\
\hline
\end{tabular}

Instructions for use 


\title{
So, What do We Know and What do We Need to Know more about the Population Ecology of the Vole Clethrionomys rufocanus?
}

\author{
Nils Chr. StenSETH ${ }^{1), *}$ and Takashi SaitoH ${ }^{2), *}$
}

1) Division of Zoology, Department of Biology, University of Oslo, P.O. Box 1050 Blindern, N-0316 Oslo, Norway

2) Hokkaido Research Center, Forestry and Forest Products Research Institute, Sapporo 062-8516, Japan

* Centre for Advanced Study, Norwegian Academy of Science and Letters, Drammensveien 78, N-0271 Oslo, Norway

\begin{abstract}
“臼なら君に睨をれたら百年目だろら” (“But when it comes to rats, I expect you just pin them down with one hypnotic glare." In I am a cat (1905-07))

"En normalt bygget sandhed lever - lad mig sige - $i$ regelen en 17-18, hojst 20 àr; sjelden loengre." ("An ordinary truth does generally not last - let me say - for more than 17-18 years, at most 20 years; only rarely longer." In An enemy of the people $(1882))^{3)}$
\end{abstract}

The purpose of this Special Feature on the population ecology of Clethrionomys rufocanus (Sundevall, 1846) has been to assess our knowledge on the spatiotemporal dynamics in this vole species in Hokkaido, the northernmost island of Japan. Beside reviewing and summarizing our understanding of the species in Hokkaido, we have throughout been aiming at viewing the obtained insight both within a general framework of microtine rodent ecology as well as within ecology in a more general context (see, e.g. Stenseth et al. 1998a).

In this concluding paper, we try pulling together what we know about the population ecology of $C$. rufocanus and where we most profitably ought to move next.

\footnotetext{
1) E-mail: n.c.stenseth@bio.uio.no

2)E-mail: bedford@ffpri-hkd.affrc.go.jp

3) Science - be it modern or traditional - is an essential part of our culture. Because of this and due to the fact that this Special Feature, and much of the scientific work reported in it, is a direct result of a Japanese-Norwegian collaboration, we present here some Japanese and Norwegian quotes (quoted in their original language and in translation) to emphasize the international character of science. Soseki Natsume (1867-1916) was a scholar of English literature and a novelist who has been deeply loved by Japanese; he struggled with a culture gap between the West and the East. We let him convey the Japanese spirit. Henrik Ibsen (1828-1906) is probably the internationally best known Norwegian author - having profoundly influenced how to write stageplays. We let him convey the Norwegian spirit.
}

\section{What do we know?}

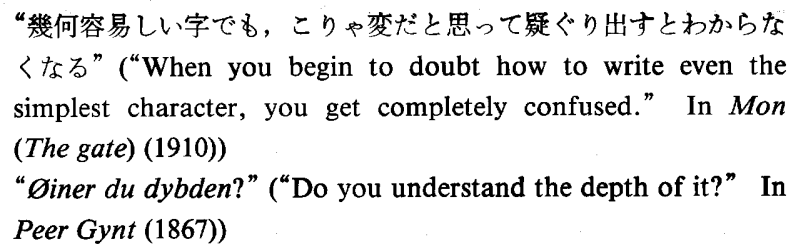

The following aspects have been rather thoroughly investigated:

1. In Hokkaido we find both multiannually periodic populations (superimposed upon seasonal changes) as well as purely seasonally fluctuating populations of Clethrionomys rufocanus: populations in the northeastern part of the island exhibit clear multiannual cycles whereas in the south and western part of the island only seasonal dynamics is observed (Bjørnstad et al. 1998a; Saitoh et al. 1998a). The gradient, which we see in Hokkaido, seems to correspond to the transition zone around $60^{\circ} \mathrm{N}$ in Fennoscandia (cf. Hansson and Henttonen 1998).

2. There is a strong degree of direct density-dependence in essentially all studied populations of $C$. rufocanus in Hokkaido. The presence of delayed density-dependence is less frequent; however, clear delayed density-dependence is found in the more clearly multiannually cyclic regions of the island (Saitoh et al. 1998a; see also Saitoh et al. 1997, 1998b).

3. Density-dependence (particularly direct density-dependence) is stronger in the northeastern populations. This geographic gradient is similar to that in temporal variability (Saitoh et al. 1998a; Stenseth et al. 1998b).

4. The spatial scale with respect to population dynamics is of the order of $50 \mathrm{~km}$ - a scale which is too large to be accounted for by movements of individual voles and consequently may reasonably be assumed due to 
some external factors (see Bjørnstad et al. 1998b).

5. The length of summer, during which essentially all reproduction occurs, is a good predictor of whether or not a region is cyclic (see Stenseth et al. 1998b); density regulation is, however, found to be strongest during winter. The differences in the relative length of the seasons (and hence the overall annual strength of density regulation) also seems to explain the observed gradient in population dynamics (cf. Bjørnstad et al. 1998a; Saitoh et al. 1998a).

6. General life history of $C$. rufocanus is well known in Hokkaido: basic information about the breeding season, gestation period, litter size, maturation age, food habits, habitats and interspecific relationships are available (Kaneko et al. 1998; see also Ota 1984). Social organization (e.g. female territoriality) and dispersal behavior (e.g. male-biased dispersal pattern) are also well known (Ishibashi et al. 1998a).

7. Although the evidence from the demographic analyses using capture-mark-recapture data is unclear due to small sample sizes, survival rate seems to be lower in high-density years; there is also rather strong evidence of reduced survival in the spring of lowdensity years (Yoccoz et al. 1998). Analyses using a seasonal matrix model suggest that the level of winter survival rate has a profound effect on population growth when winter is longer, and that adult survival and reproduction are equally important during summer (Yoccoz et al. 1998).

8. Spatial genetic structure (at a smaller spatial scale than the population level of organization) is revealed by DNA analyses; females often aggregate in kin-cluster whereas males are genetically more randomly distributed (Ishibashi 1998a, b; see also Kawata 1985; Ishibashi et al. 1997). Most voles form wintering groups based on their maternal family. The maternal families in winter thus bring about female kin-clusters in spring, which may influence reproductive output during the breeding season.

9. Clethrionomys rufocanus of Hokkaido may appropriately be considered a keystone species in the boreallike forest of Hokkaido; many carnivorous species feed mainly on this vole species which itself may affect the vegetation it depends on (particularly during peak densities and then possibly during the winter; Kaneko

- et al. 1998). Saitoh and Takahashi (1998) demonstrated a close relation between $C$. rufocanus and foxes through the infection rate of the parasite Echinococcus multilocularis in the field.

\section{What do we not yet know?}

\author{
“迷える子 - 解って?” (“Stray sheep - do you understand the \\ meaning?” In Sanshiro (1908)) \\ "Kom senerehen til andre resultater." ("Arrived later at differ- \\ ent results.” In Peer Gynt (1867))
}

We know much less about the following aspects:

1. What mechanisms do lead to the observed direct density-dependence found in essentially all populations (see Saitoh et al. 1998a)?

2. What mechanisms do lead to the observed delayed density-dependence (found in the periodically fluctuating populations; see Saitoh et al. 1998a)?

3. Even though the relative length of the seasons has been demonstrated to be a good proxy-predictor of multiannual dynamics and to explain the gradients in several population dynamics features observed in Hokkaido, we do not know enough about the underlying mechanisms (cf. Stenseth et al. 1998b). In particular, do we know very little about processes operating during the winter. Both intrinsic (social) and extrinsic factors (such as climate, vegetation and predation) may be important in generating the observed dynamics - including the density-dependencies, the cycles and the gradients.

4. We know very little about the diet - and possible temporal and spatial changes in the diet - of C. rufocanus in Hokkaido (cf. Hansson 1985).

5. We know very little about the dynamics of the trophic interactions within which $C$. rufocanus seems to play a keystone role; neither do we know enough about the predator-prey interactions nor about the plantherbivore interactions (cf. Stenseth et al. 1996).

6. Even though we have a fair general knowledge about the life history of the species, we know little about body weight changes - including size dimorphism both in time and space (cf. Yoccoz and Mesnager 1998).

7. Many other details of demography are also poorly known for C. rufocanus in Hokkaido (cf. Kaneko et al. 1998; Yoccoz et al. 1998); in particular, we know essentially nothing about how demographic rates vary among regions with different dynamic behaviors.

8. We have just begun to study the role of kinship in the social organization (Ishibashi et al. 1998a, b); much remains unclear with respect to the differences between the social organization during the winter and the summer. 


\section{What next?}

“いくら熾烈な感情が然えていても，彼は無闇には動けないのです” ("Even though his feeling is burning, he is unable to act rashly." In Kokoro (The mind) (1914))

"Udigtede kvad er stedse de fagreste." ("Unwritten verses are still the most beautiful ones." In The Pretenders (1863))

On the basis of our review on the population ecology of Clethrionomys rufocanus in Hokkaido, we suggest that it may be rewarding to undertake the following ecological and interdisciplinary - studies:

1. The extensive monitoring program of the vole populations in Hokkaido will continue to provide a gold mine for population ecologists; the existing data will become - we are sure - a benchmark data-set for ecologists and statisticians in the years to come (cf. Stenseth et al. 1998a). Unfortunately, this monitoring program faded out by 1995 , as a result of changes in silviculture practices reducing the practical need for a continued monitoring program (see, e.g. Kaneko et al. 1998). From a scientific point of view, this is unfortunate since a continuation of this monitoring program would have had an added-value-effect of each additional year far beyond the investments per each additional year. Nevertheless, it is not realistic to reestablish the monitoring program according to the original protocol. What should be done, however, is to continue monitoring at some selected sites (Krebs 1998) - for instance, along a transect of carefully selected trapping locations from the southwestern part of the island to the northeastern part.

2. The nature of the Hokkaido monitoring data is such that they are especially suited for tackling issues relating to spatial features of population dynamics (see, e.g. Bjørnstad et al. 1998a, b). One particular feature of the Hokkaido data which will make them of prime interest to statisticians and ecologists in the years to come, is the fact that the same overall structure (but with partially different parameter values) is observed at many locations within the island of Hokkaido - i.e. the data are what statisticians call panel data (see, e.g. Chan et al. 1998; Yao et al. 1998). The Hokkaido data on $C$. rufocanus may come to play the same roles in ecology and statistics as the lynx data have played in these field until now (see, e.g. Tong 1990; Stenseth et al. 1997). It is our hope that this Special Feature may serve as a platform for such future work in the interface of ecology and statistics - where ecologists can obtain new insights into ecological patterns and processes, and where statisticians are faced with rewarding challenges in connection with the develop- ment of (greatly needed) new methods designed for dealing with short time series as encountered in the field of ecology.

3. Differences in life history features may result in various types of population dynamics (Hansson and Henttonen 1985). Although some geographic variations in the length of the breeding season are known in the gray-sided vole in Hokkaido (Kaneko et al. 1998; see also Ota 1984), much further studies on life history variations are needed.

4. Based upon the findings reported by Bjørnstad et al. (1998b) on Clethrionomys and Apodemus, a speciescomparative population genetics study should be undertaken along some transect from the southwestern non-cyclic region of Hokkaido to the northeastern cyclic region of Hokkaido (see item 1 above); along such a large-scale transect, several shorter transects should be sampled. (From the study of Bjørnstad et al. (1998b) the predictions seem clear: Clethrionomys is expected to have a more coarse-grained spatial structure than Apodemus - in spite of Clethrionomys being more philopatric than Apodemus. Molecular techniques will be useful tools to clarify the spatial scales (Stacy et al. 1997; Ishibashi et al. 1998a).) Such a large-scale transect might be on the order of $500 \mathrm{~km}$ long. If the 'large' spatial scale is on the order of $50 \mathrm{~km}$ (see Bjørnstad et al. 1998b), then sampling about every $25 \mathrm{~km}$ would be appropriate. Then, at an even smaller scale, one would need to sample at much shorter distances (e.g. every $2 \mathrm{~km}$ ).

5. We certainly need to know more about the predators preying on C. rufocanus in Hokkaido - both specialized and generalized predators. We first of all need to know more about the distribution and abundance of various predators throughout the island of Hokkaido. We would furthermore need to know the effect of the voles on various predators as well as the effect of various predator species on the vole. Both observational and experimental studies are needed

6. The dynamic interactions between $C$. rufocanus and their food resources need to be better understood. Experimental studies are particularly needed here.

7. Other systems with similar gradients in ecological dynamics should be investigated in order to obtain comparable data needed for examining the generality of much of the insight summarized in this Special Feature on C. rufocanus in Hokkaido; see in this connection Hansson and Henttonen (1998).

8. One of the classic controversies in ecology has been the issue of the relative importance of densitydependent and density-independent factors (see, e.g. Nicholson 1933, 1954; Andrewartha and Birch 1954; Grenfell and Finkenstädt 1998). The fact that different parts of the island of Hokkaido is exposed to 
different climatic regimes (see Kaneko et al. 1998) makes the $C$. rufocanus of Hokkaido an ideal system to study for that purpose. Both observational and comparative experimental studies (involving different geographic regions) will be needed.

9. Seasonality has long been appreciated as potentially important for understanding the multiannual periodic oscillations of northern microtines (e.g. Ostfeld and Tamarin 1986; Hansson 1987; Saitoh 1987). Nevertheless, seasonality has not been paid much attention to by theorists (but see Hanski et al. 1993; Turchin and Ostfeld 1997; Turchin and Hanski 1997; see also Hansen et al. 1998). Stenseth et al. (1998b) incorporated the length of the summer season explicitly into a population model and thus showed that the relative length of the summer seems to be able to account for much of the observed variation in population dynamics seen in the C. rufocanus in Hokkaido ${ }^{4)}$. The theoretical proposition of Stenseth et al. (1998b) certainly needs to be tested experimentally - for instance, by taking a comparative approach involving populations from the southwestern non-cyclic region of Hokkaido and populations from the northeastern cyclic region of Hokkaido. Such studies will indeed be of great general interest (cf. Grenfell and Finkenstädt 1998).

10. In order to test the suggestion by Stenseth et al. (1998b) relating to the importance of the relative length of the different seasons, we may ask whether longer winters result in larger decreases just because of the direct effect of the winter length, without differential density-dependent effects, or whether longer winters result also in stronger density-dependent effects by, for example, reducing the monthly winter and spring survival rates. In this connection, it should be realized that the seasonal model presented by Stenseth et al. (1998b) may be written as a model using demographic rates explicitly (see Yoccoz et al. 1998): Thus, $\quad N_{t}=N_{t-1}\left(B(\bullet) s_{s, j u v}(\bullet)+s_{s, a d}(\bullet)\right) s_{w}(\bullet)$, where $B(\bullet)$ is some function representing the reproductive rate, $\mathbf{s}_{s, j u v}(\bullet)$ is some function describing juvenile survival during summer (when juveniles are found), $s_{s, a d}(\bullet)$ is some function describing adult survival during summer and $s_{w}(\bullet)$ is the corresponding rate-function during winter. The results of Stenseth et al. (1998b) suggest that the strength of density-dependence in winter demographic rates (i.e. survival)

4) Grenfell and Finkenstädt (1998) suggested that seasonal data should be analyzed. Such analysis is already underway. Referring to a Fennoscandian $C$. rufocanus population, Hansen et al. (1998) has already done such analysis based on bivariate time series modeling of spring and fall samples; for the $C$. rufocanus system in Hokkaido, we will for sure be able to go into more details, both because three samples exist for each year as well as due to the large number of sites monitored (and hence due to the resulting extensive spatial coverage). are expected to be stronger than the strength of density-dependence in summer demographic rates (i.e. summer survival and reproduction). Further work on C. rufocanus in Hokkaido along the lines suggested by Yoccoz et al. (1998) and Stenseth et al. (1998b) may indeed be very rewarding.

11. The observation that the length of the breeding season in the region with periodically fluctuating populations may be density-dependent (Fujimaki 1969; Nakata 1989), needs further investigations. Particularly do we need to understand better the dynamic consequences of such density-dependency (cf. Stenseth 1985a, b; Stenseth and Fagerström 1986; Stenseth and Antonsen 1988). Furthermore do we need to know to what extent such a density-dependency is compatible with the hypothesized phenomenological model presented by Stenseth et al. (1998b). Both observational and experimental studies, as well as theoretical ones, are required for this purpose.

12. Experimental and observational studies are needed to clarify several issues relating to the social structure of the populations. Animals are unevenly distributed and the range of individual interactions is restricted (e.g. female kin-clusters are found in C. rufocanus; Ishibashi et al. 1997). Such a clustering may have profound effects on demography (Lambin and Krebs 1991, 1993; Lambin and Yoccoz 1998; Ishibashi et al. 1998b); hence, the small spatial scale phenomena at individual level could influence larger-scaled phenomena (e.g. Stacy et al. 1997; Bjørnstad et al. 1998b). Genetic information using molecular techniques is inevitably required to analyze interaction at individual level (Ishibashi et al. 1998a). [Incidentally, reading commentaries to the main papers of the Special Feature, it is indeed noticeable that the old controversy of the importance of social factors in the shaping of the microtine rodent cycle still is alive.]

13. The findings by Ishibashi et al. (1998b) demonstrating that immature fall-born females stayed at their natal site and survived the winter, whereas most reproductively active fall-born females disperse from their natal site in the fall and died during the winter, may be one of the keys to understand density-dependent decline of voles during winter (Gliwicz 1998). Further work on the winter-demography along the lines suggested by Yoccoz et al. (1998), Stenseth et al. (1998b) and Gliwicz (1998) are likely to be highly rewarding.

14. Mechanisms explaining the alternation between low and high density years need to be better understood (see, e.g. Yoccoz et al. 1998). Papers of this Special Feature suggest that plausible hypotheses would be 1) that lower survival during winter may follow high fall densities, or 2) that lower survival of reproducing adults of spring (and possibly summer) of low-density 
years, may be closely related to pre-weaning survival rates (see Lambin and Yoccoz 1998).

Above all, it will be rewarding to design a large scale - and pluralistic (cf. Stenseth et al. (1998a) - research program tackling some of the above challenges along some transect cutting through different vegetation zones and regions with different dynamics patterns of $C$. rufocanus. The most important challenge on the next stage is to seek for mechanisms behind the patterns of population changes (Krebs 1998). Though the effect of social factors on the demography and population dynamics remain intriguing (Lambin 1998), ecological interactions at various trophic levels should also be taken in consideration (Hansson and Henttonen 1998; Ostfeld 1998). The Clethrionomys rufocanus system in Hokkaido may serve as an ideal model system for a synthetic study of broad interest in population ecology (Begon 1998). We are convinced that many Japanese and international scientists would be willing to join forces in such an effort (Itô 1998) - and benefit from doing so - scientifically and culturally. Throughout we should remember that searching for - and interpreting patterns is the core of ecology (MacArthur 1972; May 1986). This can only be done by adopting a pluralistic approach (cf. Stenseth et al. 1998a), including both theoretical and empirical studies. It seems appropriate to end by reminding ourselves about what one of the Giants within the field of ecology - who combined both theoretical and empirical studies - Robert MacArthur (1972; p. 253) once said:

\footnotetext{
"Scientists are perennially aware that it is best not to trust theory until it is confirmed by evidence. It is equally true, ..., that it is best not to put too much faith in facts until they have been confirmed by theory."
}

For the C. rufocanus of Hokkaido, much data exist - and quite a lot of rather detailed insight exists. We can hardly think of a better ecological system for confronting 'theories' and 'facts'. Let us join forces and pursue the study of this system further on the basis provided by this Special Feature - and thereby proceeding beyond "the end of the beginning".

\section{References}

Andrewartha, H. G. and L. C. Birch (1954) The distribution and abundance of animals. University of Chicago Press, Chicago.

Begon, M. (1998) The vole Clethrionomys rufocanus - a modern classic. Researches on Population Ecology 40: 145-147.

Bjørnstad, O. N., N. C. Stenseth, T. Saitoh and O.C. Lingjærde (1998a) Mapping the regional transition to cyclicity in Clethrionomys rufocanus: spectral densities and functional data analysis. Researches on Population Ecology 40: 77-84.
Bjørnstad, O. N., N. C. Stenseth and T. Saitoh (1998b) Synchrony and scaling in dynamics of voles and mice in northern Japan. Ecology (in press).

Chan, K.-S., H. Tong and N. C. Stenseth (1998) Analyzing abundance data from periodically fluctuating rodent populations by threshold models: a nearest neighbour bootstrap approach. (in review).

Fujimaki, Y. (1969) The fluctuations in the number of small rodents. Bulletin of the Hokkaido Forest Experiment Station 7: 62-77 (in Japanese with English summary) .

Gliwicz, J. (1998) Winter in Hokkaido. Researches on Population Ecology 40: 135-136.

Grenfell, B. T. and B. F. Finkenstädt (1998) Seasonality, stochasticity and population cycles. Researches on Population Ecology 40: 141-143.

Hansen, T., N. C. Stenseth and H. Henttonen (1998) Multiannual vole cycles and population regulation during long winters: an analysis of seasonal density dependence. American Naturalist. (in review).

Hanski, I., I. P. Woiwod and J. Perry (1993) Density dependence, population persistence, and largely futile arguments. Oecologia 95 : 595-598.

Hansson, L. (1985) Geographic differences in bank voles Clethrionomys glareolus in relation to ecogeographical rules and possible demographic and nutritive strategies. Annales Zoologici Fennici 22: 319-328.

Hansson, L. (1987) An interpretation of rodent dynamics as due to trophic interactions. Oikos 50: 308-318.

Hansson, L. and H. Henttonen (1985) Regional differences in cyclicity and reproduction in Clethrionomys species: Are they related? Annales Zoologici Fennici 22: 277-288.

Hansson, L. and H. Henttonen (1998) Rodent fluctuations in relation to seasonality in Fennoscandia and Hokkaido. Researches on Population Ecology 40: 127-129.

Ishibashi, Y., T. Saitoh, S. Abe and M. C. Yoshida (1997) Sexrelated spatial kin structure in a spring population of grey-sided voles Clethrionomys rufocanus as revealed by mitochondrial and microsatellite DNA analyses. Molecular Ecology 6: 63-71.

Ishibashi, Y., T. Saitoh and M. Kawata (1998a) Social organization of the vole Clethrionomys rufocanus and its demographic and genetic consequences: a review. Researches on Population Ecology 40: $39-50$.

Ishibashi, Y., T. Saitoh, S. Abe and M. C. Yoshida (1998b) Kinrelated social organization in a winter population of the vole Clethrionomys rufocanus. Researches on Population Ecology 40: 51-59.

Itô, Y. (1998) Lemmings and voles: present and future. Researches on Population Ecology 40: 149-151.

Kaneko, Y., K. Nakata, T. Saitoh, N. C. Stenseth and O. N. Bjørnstad (1998) The biology of the vole Clethrionomys rufocanus: a review. Researches on Population Ecology 40: 21-37.

Kawata, M. (1985) Sex differences in the spatial distribution of genotypes in the red-backed vole, Clethrionomys rufocanus bedfordiae. Journal of Mammalogy 66: 384-387.

Krebs, C. J. (1998) Whither small rodent population studies? Researches on Population Ecology 40: 123-125.

Lambin, X. (1998) Gradients in cyclicity, predation and microtine life history. Researches on Population Ecology 40: 137-139.

Lambin, X. and C. J. Krebs (1991) Can changes in female relatedness influence microtine population dynamics? Oikos 61: 126-132.

Lambin, X. and C. J. Krebs (1993) Influence of female relatedness on the demography of Townsend's vole populations in spring. Journal of Animal Ecology 62: 536-550. 
Lambin, X. and N. G. Yoccoz (1998) The impact of population kin-structure on nestling survival in Townsend's voles, Microtus townsendii. Journal of Animal Ecology 67: 1-16.

MacArthur, R. H. (1972) Geographical ecology. Harper and Row, New York.

May, R. M. (1986) The search for patterns in the balance of nature: advance and retreat. Ecology 67: 1115-1126.

Nakata, K. (1989) Regulation of reproduction rate in a cyclic population of the red-backed vole, Clethrionomys rufocanus bedfordiae. Researches on Population Ecology 31: 185-209.

Nicholson, A. J. (1933) The balance of animal populations. Journal of Animal Ecology Supplement 2: 132-178.

Nicholson, A. J. (1954) An outline of the dynamics of animal populations. Australian Journal of Zoology 2: 9-65.

Ota, K. (1984) Study on wild murid rodents in Hokkaido. Hokkaido University Press, Sapporo (in Japanese).

Ostfeld, R.S. (1998) The importance of interactions in the population ecology of the Vole. Researches on Population Ecology 40: 131-133.

Ostfeld, R. S. and R. H. Tamarin (1986) The role of seasonality in vole cycles. Canadian Journal of Zoology 64: 2871-2872.

Saitoh, T. (1987) A time series and geographical analysis of population dynamics of the red-backed vole in Hokkaido, Japan. Oecologia 73: 382-388.

Saitoh, T. and K. Takahashi (1998) The role of vole populations in prevalence of the parasite (Echinococcus multilocularis) in foxes. Researches on Population Ecology 40: 97-105.

Saitoh, T., N. C. Stenseth and O. N. Bjørnstad (1997) Density dependence in fluctuating grey-sided vole populations. Journal of Animal Ecology 66: 14-24.

Saitoh, T., N. C. Stenseth and O. N. Bjørnstad (1998a) The population dynamics of the vole Clethrionomys rufocanus in Hokkaido, Japan. Researches on Population Ecology 40: 61-76.

Saitoh, T., O. N. Bjørnstad and N. C. Stenseth (1998b) Densitydependence in voles and mice: a comparative study. Ecology (in press).

Stacy, J. E., P. E. Jorde, H. Steen, R. A. Ims, A. Purvis and K. S. Jakobsen (1997) Lack of concordance between mtDNA gene flow and population density fluctuations in the bank vole. Molecular Ecology 6: 751-759.

Stenseth, N. C. (1985a) Models of bank vole and wood mouse populations. Symposium of the Zoological Society of London 55: 339-376.
Stenseth, N.C. (1985b) Population dynamics consequences of female territoriality in bank voles. Acta Theriologica 28: $445-460$.

Stenseth, N. C. and B. J. Antonsen (1988) Density dependence and microtine cycle II. A discrete time model for a synchronously reproducing population. Oikos 52: 207-211.

Stenseth, N. C. and T. Fagerström (1986) Population density regulation in Clethrionomys: the effect of changing litter size and length of reproduction season. Acta Theriologica 31: 365-382.

Stenseth, N. C., O. N. Bjørnstad and W. Falck (1996) Is spacing behaviour coupled with predation causing the microtine density cycle? A synthesis of process-oriented and pattern-oriented studies. Proceedings of the Royal Society of London B 263: 1423-1435.

Stenseth, N. C., W. Falck, O. N. Bjørnstad and C. J. Krebs (1997) Population regulation in snowshoe hare and lynx populations: asymmetric food web configurations between the snowshoe hare and the lynx. Proceedings of the National Academy of Science of the USA 94: 5147-5152.

Stenseth, N. C., T. Saitoh and N. G. Yoccoz (1998a) Frontiers in population ecology of microtine rodents: a pluralistic approach to the study of population ecology. Researches on Population Ecology 40: 5-20.

Stenseth, N. C., O. N. Bjørnstad and T. Saitoh (1998b) Seasonal forcing on the dynamics of Clethrionomys rufocanus: modeling geographic gradients in population dynamics. Researches on Population Ecology 40: 85-95.

Tong, H. (1990) Non-linear time series: a dynamical system approach. Oxford University Press, Oxford.

Turchin, P. and I. Hanski (1997) An empirically based model for latitudinal gradient in vole population dynamics. American Naturalist 149: 842-874.

Turchin P. and R. S. Ostfeld (1997) Effects of density and season on the population rate of change in the meadow vole. Oikos 78: 355361.

Yao, Q., H. Tong, B. Finkenstädt and N. C. Stenseth (1998) Common structure in panels of short time series. (in review).

Yoccoz, N. G. and S. Mesnager (1998) Are alpine bank voles larger and more sexually dimorphic because adults survive better? Oikos 82: 85-98.

Yoccoz, N. G., K. Nakata, N. C. Stenseth and T. Saitoh (1998) The demography of the vole Clethrionomys rufocanus: from mathematical and statistical models to further field studies. Researches on Population Ecology 40: 107-121. 